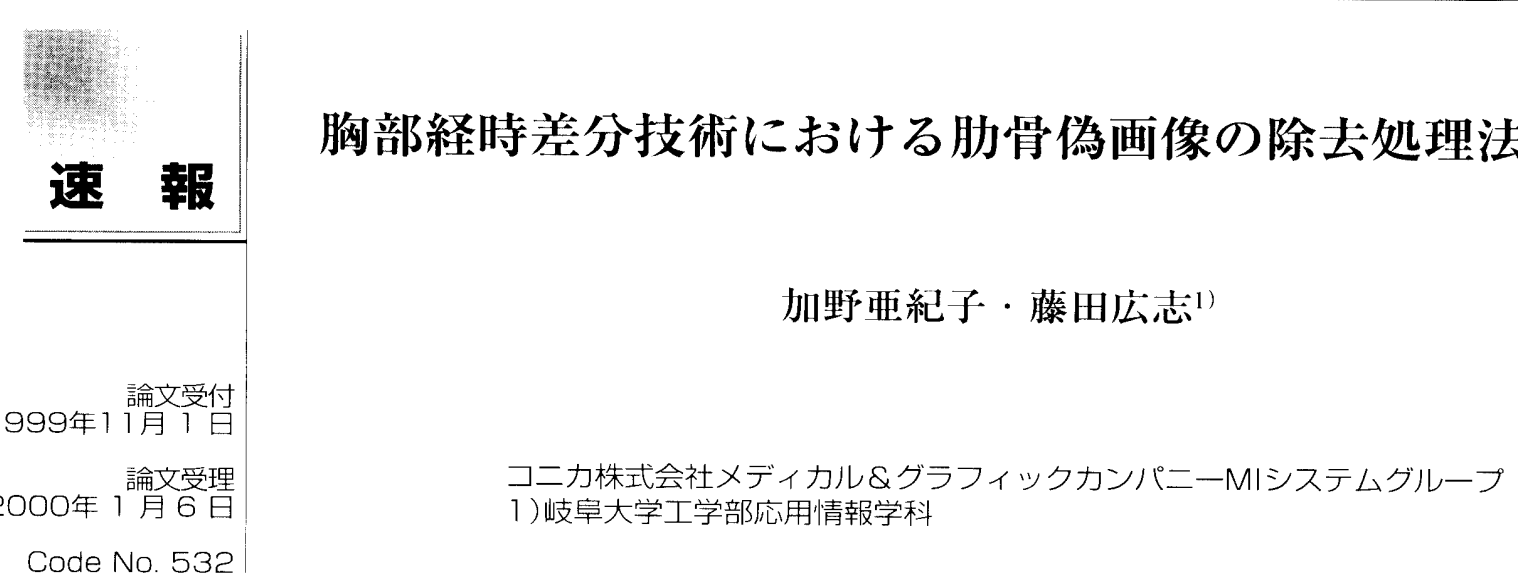

\section{緒 言}

異なる時期に撮影された同一患者の胸部X線丒像間の

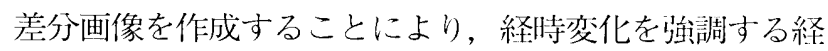
時差分処理は，胸部診断支援技術の一つとして知られて いる．筆者らは，自動重祊合わせ処理を用いた経時差分 処理およびその評価に関する研究を行ってきた1.2)。経 時差分画像の提示は，医師の読影精度を们上させる可能 性があることが報告されている3.4!。これは，差分画像 においては，正常構造が消去されたほぼ一様な背志の上 に，病変陰影が周囲との信号差を持つパターンとして描 出されるためであると考えられる。

2 回の胸部X線撮影間の撮影体位の差異は, 善分画 像に拈ける正常構造の完全な消去を困難にし，正常構 造の位置ずれによる偽画像を生じさせる。この偽画像 の中で高コントラストを有するのは胁骨等の骨に由米 する陰影であるが，たとえば体の前後力向の傾きによ る胁骨エッジ変位に起因する偽画像(以下，肋骨偽画 像)は，医師による診断能の问上に悪影響を及ぼさな いことが報告されている゙!。

本研究では, 差分画像上に現れる経時変化陰影を, 背景との信号差を利用して抽出した後に，偽陽性の要 因となる胁骨偽画像を判別して，候補除影加ら除外す
る処理を検討したので報告する。

\section{1. 方 法}

\section{1-1 経時差分画像の作成}

マトリクスサイズ $1,024 \times 1,024$ ，階調数 12 bitのディ ジタルX線画像を使用し，同一患者の 2 枚の時系列的 な胛部醉像に対して，古でに報告済みの非線形画像変 形に基づく白動重权合わせ処理122を稒用することに より胸部構造の位置合わせを行った後に，過去画像の 画素值から新しい画像の䤂值を減算する。

\section{1-2 経時変化陰影の自動抽出}

\section{1-2-1 候補陰影の抽出}

得られた経時差:分画像に䦨値処理を施し，背景に比 ベて高信号値のパターンを抽出する。閾值としては, 画像を $128 \times 128$ の矩形部分領域に分割し, 部分領域ご とに[部分領域内の平均信号值 + 一定值]の值を用い る. 抽山された領琙に対しラベリング処理を行う。次 に，本研究の検出刘象とする病変のうち最小のものを 直径 $5 \mathrm{~mm}$ 前後の結節性㓌影と想定し，面積が実物大 擙算で $3 \mathrm{~mm}^{2}$ (直径約 $2 \mathrm{~mm}$ の门に相当) 以下である微小 領域を族変と関係のない㓌影とみなして削除する。

\title{
Automated Elimination of Rib Edge Artifacts in Chest Temporal Subtraction Technique
}

\section{AKIKO KANO and HIROSHI FUJITA ${ }^{1)}$}

MI System Department, Medical \& Graphic Company, Konica Corporation 1 ) Department of Information Science. Faculty of Engineering. Gifu University Received Nov. 1, 1999; Revision accepted Jan. 6, 2000; Code No. 532

Key words: Digital image subtraction, Interval change, Misregistration artifact, Chest radiograph, Computer-aided diagnosis 


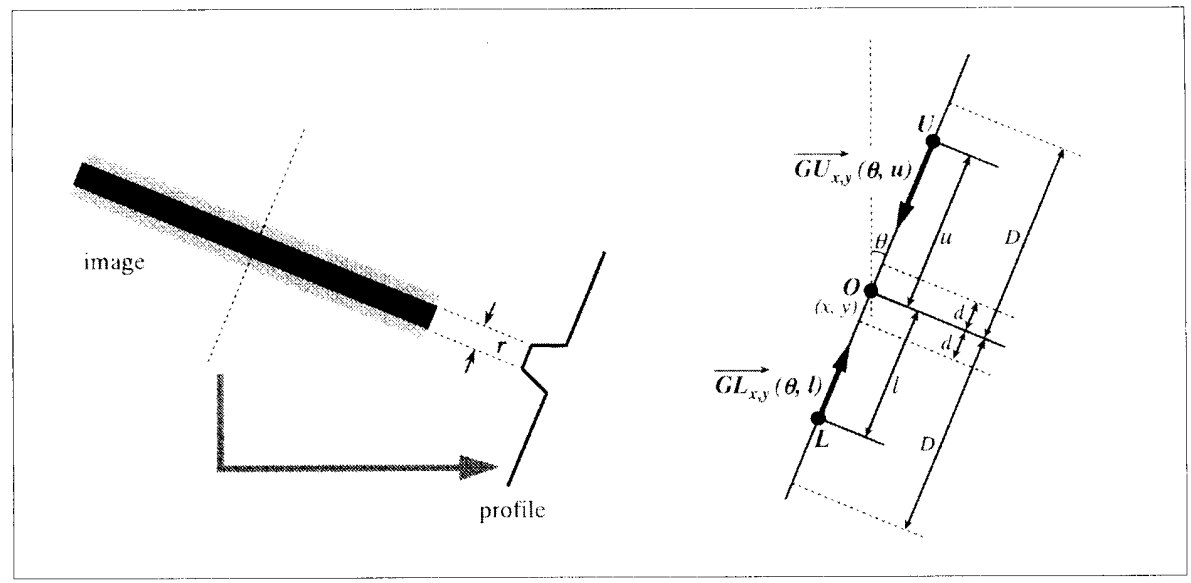

Fig. 1 lllustration of a rib edge misregistration artifact.

(a) Model for a rib edge misregistration artifact and its image profile.

$a \mid b$

(b) Definition of gradation vectors for calculation of the "ridge filter."

\section{1-2-2 肋骨偽画像の認識}

Sobel才ペレータを用いて信号值创配を計算する。 ここで, Sobel才ペレータのマスクサイズとしては, 胁省偽画像エッジを最も効果的に強調するよう垁験的 に定めた值である11画素を用いたＦFig.1aの胁省偽画 像モデルを想定し， $r$ 部分を強調する日的で新規に考 条したridge filter孝適用する。注目画絭 $O(x, y)$ に刘市 る $\theta$ 方向 $(-\pi / 4 \leq \theta \leq \pi / 4)$ のridge filter出力值 $R_{\text {s. }}(\theta)$ を次式で是義する。

$$
R_{x, y}(\theta)=\max _{d \leq u \leq D} \overline{G U_{x, y}}(\theta, u)+\max _{d \leq l \leq D} \overline{G L_{x, y}}(\theta, l)
$$

ここで, $\overline{G U_{k, y}}(\theta, u)$ および $\overline{G L \ldots y}(\theta, l)$ は，おのおの Fig.1bに四示する点U拉よびLからOに向かう信昌值公 配ベクトルの大きさを表す.

肋骨偽画像は，肋骨のト下エッジに沿って高信珰と 低信号の …つの㓌影がペアを構成する。また胁省の幅 は一枚の胸部画像の中ではほぼ一定である。そこで， 注H画素と，y方向にw(wは整数)だけ離れた画素 $(x, y+w)$ とのridge filter出力の差分B $B_{. y}(w)$ を定義し, 画像 $I$ 内の $B_{x, y}(w)$ の総和を $S(w)$ と表す.

$$
\begin{aligned}
& S(w)=\sum_{(,, y) \in l} B_{x, y}(w) \quad \ldots \ldots \ldots \ldots \ldots . . \\
& B_{x, y}(w)=\max _{-\frac{\pi}{4} \leq \theta \leq \frac{\pi}{4}}\left\{R_{t, y}(\theta)-R_{t, y+w}(\theta)\right\}
\end{aligned}
$$

$S(w)$ が極大值を示す場合の $w$ の值 $w_{m}$ は胁骨の幅に ほぼ等しいとみなされる。 $w=w_{m}$ のときのB $B_{n}\left(w_{m}\right)$ を, 肋骨偽画像を判別するための指標としbone edge factorと呼ぶ.

\section{1-2-3 経時変化陰影の決定}

1-2-1で抽出された候補㓌影のおのおのについて bone edge factorの平均值を計算する。平均值力所定の 閾僧以上である㓌影を削除し, 残った陰影を経時変化 除影とみなす。

\section{2. 結 果}

まず，シミュレーション画像を用いて本手法の基本 動作を検証した．Fig.2aおよびFig.2bの（1）は，肋骨工 ッジ変位量が百いに異なる 2 種類の経時差分画像を模 した画像で，Aは师形の病変に由米する経㭙変化陰 影，B拉よびCは肋骨偽画像，Dはステップ状の信号変 化に由来する経時変化陰影(胸水の水位など)をモデル 化したものである.Fig.2aおよびFig.2bの(2)は䦨值処 理により得られた 4 個の候補除影を示す。（3）はridge filter出小，(4)は（3）に基づいて計算された bone edge

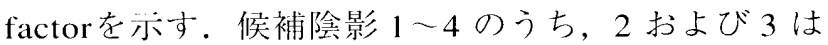
bone edge factorの平均值が大きいために削除され，

(5)に小すように1抢よび 4 が経時变化陰影として抽 出された。

Fig.3に，胸部経時差分画像の処理例の一部分を示 す。病変にかかわる変化を含む 2 個の経時変化陰影(新 たに発生した結節性㓌影 1 および肋軟骨の化骨の進行 2)が抽出され，1個の肋骨偽画像 3 が削除された。病 理的経時变化を有する胸部画像10症例の経時差分画像 から切り出した部分画像 $(256 \times 256) 10$ 画像に対して本 手法を適用した，偽㓌性の総数が 0 となるように閾值 (全画像に共通の值)を設定して処理した結果，最終的 に抽出されな経時変化陰影38個の内訳は, 病変由来の 経時変化 15 , 正管な生理的变化による経時変化 10 , 胁 骨偽画像 1 , 肺門影偽画像7，肩甲骨偽画像5であった。 候補㓌影から削除された胁咸偽画像は29個であった。 
(a)

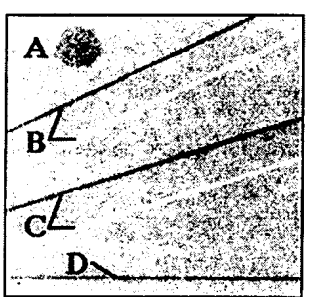

(1)

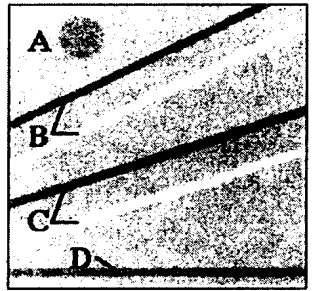

(1)

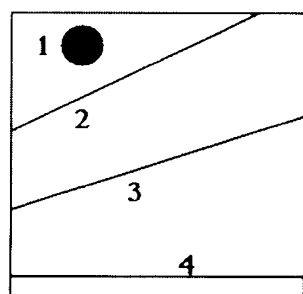

(2)

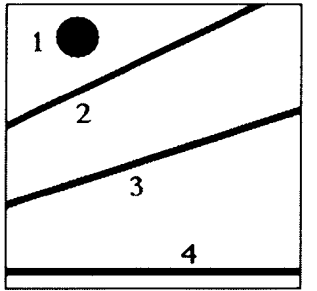

(2)

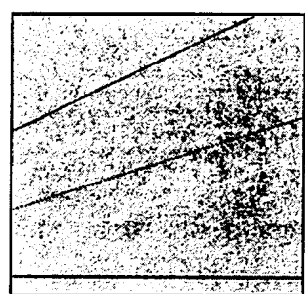

(3)

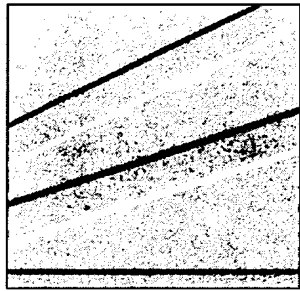

(3)

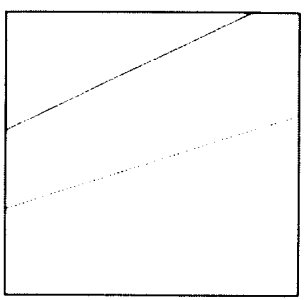

(4)

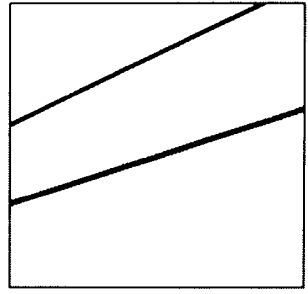

(4)

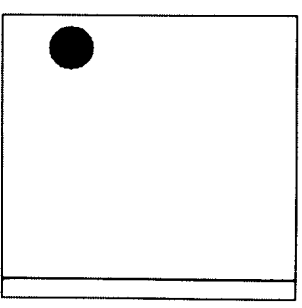

(5)

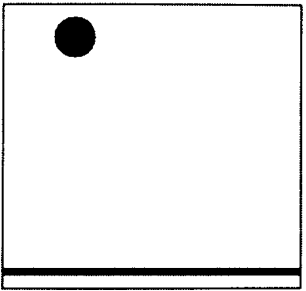

(5)

Fig. 2 Processing results for simulated subtraction images.

(a) Example of a simulated subtraction image.

(b) Another example of a simulated subtraction image with a different amount of misregistration of ribs.

(1) Subtraction image. (2) Result of thresholding. (3) Output of ridge filter. (4) Calculated bone-edge factors. (5) Final extracted patterns.
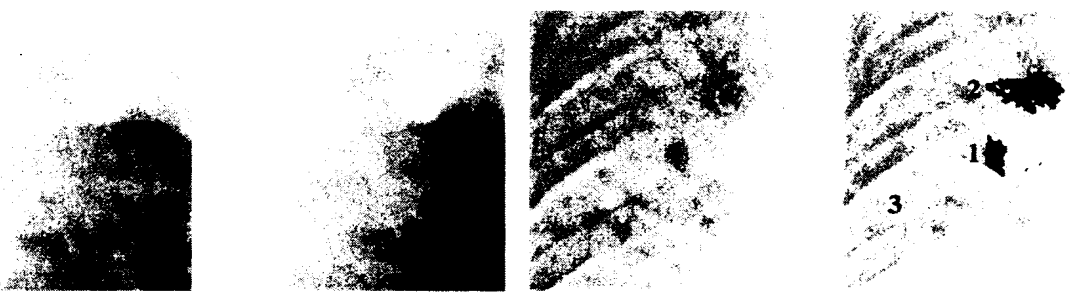

Fig. 3 Example of detection of interval change patterns.
(a) Part of a chest $x$-ray image.
(b) The corresponding part of a chest $x$-ray image of the same patient, acquired one year later.
(c) Temporal subtraction image between (a) and (b).
(d) Processing result of the proposed method.
Two black regions ( 1 and 2 ) and a white region (3) indi- cate the final extracted patterns and the pattern elimi- nated as a rib-edge artifact, respectively.

$\mathbf{a}|\mathbf{b}| \mathbf{c} \mid \mathbf{d}$

\section{3. 考 察}

シミュレーション画像により, 肋骨エッジ変位量の 大小に関わらず偽画像を削除できること, 線状陰影で あってもFig.2a(1)Dのようにペアを構成しない単独院 影は削除されないことが検証された．実際の胸部画像 の処理結果から導かれる今後の課題として, 肺門影な ど肋骨以外の正常構造に起因する偽画像を除く手法の 開発，および病変と偽画像が重なる場合の処理手法の 検討などが挙げられる. 今後, 多数の有所見症例の処 理により処理パラメータの最適化を行い，有効性を評 価するとともに, 差分画像の画質と処理結果との関連 について調査するなど，さらなる検討が必要であると 考える.

\section{4. 結 語}

経時差分画像上に現れる陰影から肋骨偽画像を除去 する目的に対して，新たに定義したridge filterおよび bone edge factorを用いた手法を提案し，予備的検討に おいて有用な結果を得ることができた。本手法に，目 的に応じた後処理を組み合わせることにより，病変陰 影の自動検出処理への発展性が期待される.

\section{謝 辞}

画像を提供していただいた愛媛大学医学部の池添潤 平教授，川上壽昭技師長はじめ諸先生方に感謝いたし ます。 


\section{参考文献}

1) Kano A, Doi K, MacMahon H, et al.: Digital image subtraction of temporally sequential chest images for detection of interval change. Med Phys, 21 (3), 453-461, (1994).

2) 加野亜紀子, 池添潤平, 安原美文, 他: 胸部集団検診X線 画像を対象とした経時差分処理における新しい自動重ね合 わせ法. 信学論次世代医用画像技術論文特集号, 揭載予 定.

3) Difazio MC, MacMahon H, Xu XW, et al.: Digital chest radiography: Effect of temporal subtraction images on detection accuracy. Radiology, 202 (2), 447-452, (1997).
4) 中村克巳, 魚住富淑弥, 高橋広行, 他：胸部写真における 経時的差分画像法の臨床的有用性. INNERVISION, 14 (10), 47-50, (1999).

5) 真田 茂：時系列胸部X線画像の差分処理画像を用いるコ ンピュー夕支援診断法の開発. 日本医放会誌, 58(14), 824-830, (1998).

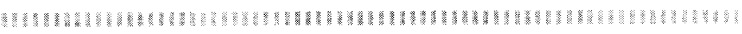

Fig. 1 肋骨エッジ変位に起因する偽画像.
(a)肋骨偽画像モデル，およびその画像プロファイル。
(b) ridge filterの計算に用いられる勾配べクトルの定義.

Fig. 2 シミュレーション画像の処理結果.
(a) 経時差分画像を模したシミュレーション画像の例.
(b) 肋骨エッジ変位量の異なるシミュレーション画像の例.
(1) 経時差分画像.（2）閾値処理の結果．（3) ridge filter出力. (4) bone edge factorの計算結果.（5)最終的に抽出された経時 変化陰影.

Fig. 3 経時変化㓌影の検出例。
(a) 胸部X線画像の一部分.
(b) 一年後に撮影された同一患者の胸部X線画像の (a)に対応する部分.
(c) (a)と (b)を用いて得られた経時差分画像.
(d) 提案手法を用いた処理結果. 黒色で示した領域 $(1,2)$ および白色で示した領域(3)は，おのおの最終的に抽出された陰 影および除去された肋骨偽画像を表す。

